Ovael Sandro Melta, M. Fachri Adnan I Upaya Pemerintah Kota Padang dalam Memberdayakan Nelayan Tradisional di Pantai Muaro Lasak Kota Padang

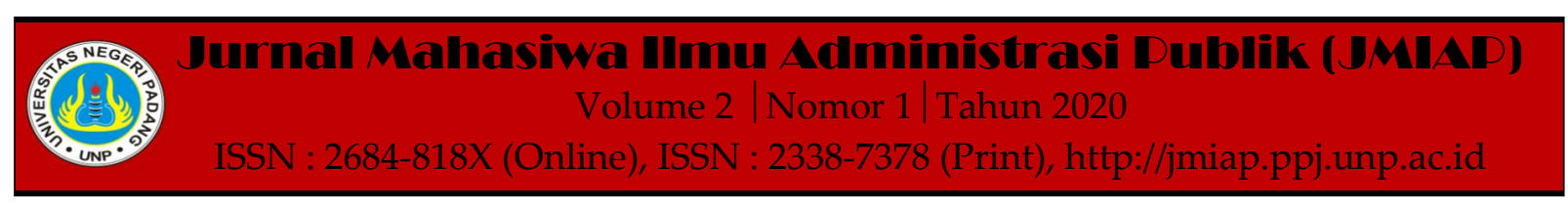

\title{
UPAYA PEMERINTAH KOTA PADANG DALAM MEMBERDAYAKAN NELAYAN TRADISIONAL DI PANTAI MUARO LASAK KOTA PADANG
}

\author{
Ovael Sandro Melta ${ }^{1(a)}$, M. Fachri Adnan'(b) \\ ${ }^{1}$ Jurusan Ilmu Administrasi Negara, Universitas Negeri Padang \\ ${ }^{2}$ Jurusan Ilmu Administrasi Negara, Universitas Negeri Padang \\ a)osmelta@gmail.com, b)fachri.adnan@gmail.com
}

\begin{abstract}
This research was conducted at the Muaro Lasak beach in Padang City with the aim of describing the efforts of the Padang city government to empower traditional fishermen on the Muaro Lasak beach in Padang city. In addition to taking data on the coast of Muaro Lasak, research will also be conducted at the Padang City Maritime and Fisheries Office to obtain directed and precise research results to find out various phenomena and events that have occurred. The data collection technique was carried out by means of observation which meant that the data collection was carried out based on the results of the direct field that occurred at Muaro Lasak beach, Padang. The data analysis technique used in this study is descriptive analysis, which provides a holistic picture of the research. Observations are made directly and indirectly to get an accurate picture to find the right data and understand. With a variety of methods, it is hoped that this research can provide a clear and precise picture to meet the data and problems that will occur later. Government efforts in empowering traditional fishermen on the coast of Muaro Lasak, Padang city are going well because the Capture Fisheries Development Program or P3T provides possibilities, reinforcement, protection, support and maintenance that help traditional fishermen in solving their problems despite experiencing some obstacles that have not been can be resolved quickly. Through the Capture Fisheries Development Program, it will be seen how the response of traditional fishermen to the program and what effects will be felt by the traditional fishermen directly through observation later.
\end{abstract}

Keywords : Traditional Fishermen, Empowerment, Capture Fisheries Development Program

Corresponding author. Email.osmelta@gmail.com,fachri.adnan@gmail.com

How to cite this article. Melta, O. Sandro \& Adnan, M. Fachri. (2020). Upaya Pemerintah Kota Padang dalam Memberdayakan Nelayan Tradisional di Pantai Muaro Lasak Kota Padang. Jurnal Mahasiwa Ilmu Administrasi Publik (JMIAP) Jurusan Ilmu Administrasi Negara Fakultas Ilmu Sosial Universitas Negeri Padang, Volume 2 (1), Hal. 77-86.

http://jmiap.ppj.unp.ac.id

ISSN : 2684-818X (Online), ISSN : 2338-7378 (Print)

Copyright $\bigcirc 2020$. Published by Pusat Kajian-Pemberdayaan dan Pelayanan Masyarakat (PK-P2M) FIS UNP Padang 


\section{PENDAHULUAN}

Kota Padang adalah ibu Kota provinsi Sumatera barat yang teletak pada Secara geografis, Kota Padang berada di antara 00 44' 00" dan 1 08' 35" Lintang Selatan serta antara 100 05' 05" dan 100 34' 09" Bujur Timur. Menurut Perda No. 10 Tahun 2005 tentang luas Kota Padang diketahui terjadi penambahan luas administrasi menjadi 1.414,96 Km2, dimana penambahan wilayah lautan/perairan seluas 720,00 km2. Memiliki wilayah perairan sebesar itu merupakan salah satu bukti kekayaan alam yang di miliki kota Padang, tidak heran sekitar ribuan nelayan dengan berbagai jenis hidup di kota padang untuk memanfaatkan hasil laut yang luas.

\section{Tabel 1. Tabel Kecamatan di Kota} Padang

\begin{tabular}{cc}
\hline No & Kecamatan \\
\hline 1 & Bungus Teluk Kabung \\
2 & Lubuk Kilangan \\
3 & Lubuk Begalung \\
4 & Padang Selatan \\
5 & Padang Timur \\
6 & Padang Barat \\
7 & Padang Utara \\
8 & Nanggalo \\
9 & Kuranji \\
10 & Pauh \\
11 & Koto Tangah \\
\hline
\end{tabular}

Nelayan merupakan sebuah profesi unggulan yang ditekuni di indonesia dahulunya karena kekayaan yang besar membuat kehidupan lebih terjamin, tahun berlalu dan zaman berkembang pesat sehingga nelayan pun mengalami perubahan yang besar juga mengikuti zaman untuk berubah mengikuti globalisasi. Tidak hanya berubah dalam sepenuhnya untuk menjadi nelayan yang lebih moderen tapi ada juga yang tetap mengikuti tradisi dengan menangkap ikan dengan cara lama meskipun tetap terpengaruh akan perubahan zaman. Maka dari itu ada 2 penyebutan nelayan - nelayan ini di sebut nelayan tradisional dan nelayan bagan, nelayan tradisional adalah nelayan yang masi melakukan profesi nelayan dengan cara yang tradisional yaitu memancing, menjaring dan menanam jaring pukek di laut sedangkan nelayan bagan adalah nelayan yang lebih moderen dengan cara penangkapan ikan melalui cantrang yang di lepas dan ditarik sepanjang perjalanan kapal untuk mengumpulkan ikan dalam waktu singkat. Kedua nelayan ini sama - sama memiliki peranan penting untuk menangkap ikan - ikan dilautan (kusnadi 2010:65) memiliki banyak nelayan - nelayan tradisional dan nelayan bagan yang masih aktif untuk menangkap ikan - ikan yang ada di lautan, nelayan - nelayan tradisional ini terbagi atas beberapa kategori sesuai dengan tabel seperti berikut: 
Ovael Sandro Melta, M. Fachri Adnan| Upaya Pemerintah Kota Padang dalam Memberdayakan Nelayan Tradisional di Pantai Muaro Lasak Kota Padang

Tabel 2. Jumlah Nelayan di Kota Padang

\begin{tabular}{clccc}
\hline \multirow{2}{*}{ No } & \multicolumn{1}{c}{ Kecamatan } & $\begin{array}{c}\text { Jumlah Nelayan } \\
\text { Penuh } \\
\text { Sambilan }\end{array}$ & Jumlah \\
& & $\mathbf{2 0 1 8}$ & $\mathbf{2 0 1 8}$ & $\mathbf{2 0 1 8}$ \\
\hline 1 & Bungus Teluk Kabung & 1585 & 130 & 1715 \\
2 & Lubuk Begalung & 981 & 114 & 1095 \\
3 & Padang Selatan & 892 & 92 & 984 \\
4 & Padang Timur & - & - & - \\
5 & Padang Barat & 397 & 23 & 420 \\
6 & Padang Utara & 663 & 50 & 713 \\
7 & Nanggalo & 30 & 8 & 38 \\
8 & Kuranji & - & - & - \\
9 & Pauh & - & - & 2111 \\
10 & Koto Tangah & 1988 & 123 & $\mathbf{7 0 7 6}$ \\
\hline
\end{tabular}

Berdasarkan tabel tersebut diketahui bahwa terdapat 7076 nelayan yang beroperasi sebagai nelayan bagan atau nelayan tradisional kedua nelayan ini memiliki potensinya masing - masing. Perbedaan antara nelayan tradisional dan nelayan bagan terletak pada ukuran kapal serta cara menangkap ikanya selain itu perbedaan lainya antara nelayan tradisional dan nelayan bagan dilihat pada zona tangkap yang ada pada peraturan Kementrian Kelautan dan Perikanan Republik Indonesia No 71 tahun 2016 tentang Jalur penangkapan ikan dan penempatan alat penangkapan ikan di wilayah pengelolaan perikanan negara republik indonesia, dimana disana tertulis akan batasan nelayan tradisional untuk menangkap ikan di mulai dari 2 mil sampai dengan 4 mil di ukur dari awal pasang surut air laut, selanjutnya batasan nelayan bagan di mulai dari 4 mil sampai dengan 12 mil maksimal terhitung dari pasang surut air laut.

Dikota Padang tepatnya di Pantai Muaro Lasak terdapat 137 nelayan tradisional yang mengalami kendala penghasilan, kendala ini terjadi akibat adanya pelanggaran jalur tangkap yang dilakukan nelayan bagan yang tidak mematuhi peraturan yang ada sehingga zona tangkap untuk nelayan ttradisional di ambil oleh nelayan bagan. Permasalahan selanjutanya adalah pantai Muaro Lasak yang sekarang berdiri telah menjadi objek wisata yang terkenal di kota Padang yang dulunya merupakan tempat aktifitas nelayan - nelayan tradisional untuk menjemur jaring, pukek dan memarkirkan kapalnya. Sekarang tempat itu tidak bisa di gunakan untuk kegiatan-kegiatan nelayan tradisional tersebut sehingga itu menjadi faktor penghambat persiapan nelayan-nelayan tradisional yang ingin melaut atau yang ingin memperbaiki kapalnya.

Berdasarkan masalah-masalah tersebut maka pentingnya pemberdayaan untuk mampu membantu nelayan-nelayan tradisional di pantai muaro lasak kota Padang. Pemerintah kota Padang dusah seharusnya memberdayakan nelayannelayan tradisional tersebut supaya nelayannelayan ini mampu berproduktifitas dengan baik dan mampu meningkatkan penghasilanya sendiri. Ada 5 langkah pemberdayaan yang harus ditempuh untuk yaitu penerapan pendekatan pemberdayaan dapat dilakukan melalui pemungkinan, penguatan, perlindungan, penyokongan dan pemeliharaan (Suharto, 2005:45). 
Pentingnya melakukan pemberdayaan adalah untuk menciptakan keseimbangan antara masyarakat kecil untuk meningkatkan penghasilanya supaya menjadikan masyarakat kecil lebih mandiri dan mampu bertindak dengan sendirinya untuk mengatasi masalah - masalah kedepanya yang akan datang, begitu juga dengan masyarakat nelayan tradisional yang merupakan kelompok nelayan sederhana yang ada untuk menangkap ikan dengan tehnik yang sederhana dan menjaga ekosistem laut karena nelayan tradisional yang masih menerapkan cara memancing dan menaruh jaring pukek di lautan memiliki potensi lebih besar menjaga keseimbangan ekosistem laut dari pada pemakaian cantrang yang justru bisa membawa ikan - ikan kecil atau bibit lanjutan yang harus ada untuk menjaga ekosistem laut tetap seimbang ( kusnadi $2010: 76)$.

\section{TINJAUAN PUSTAKA}

\section{Pendekatan Pemberdayaan}

Dalam melaksanakan pemberdayaan perlu dilakukan melalui berbagai pendekatan. Menurut Suharto (2005), penerapan pendekatan pemberdayaan dapat dilakukan melalui 5P, yaitu pemungkinan,penguatan, perlindungan, penyokongan dan pemeliharaan.

1) Pemungkinan

Pemungkinan yaitu menciptakan suasana atau iklim yang memungkinkan potensi masyarakat berkembang secara optimal. Pemberdayaan harus mampu membebaskan masyarakat dari sekaratsekarat kultural dan struktur yang menghambat.

2) Penguatan

Penguatan berarti memperkuat pengetahuan dan kemampuan yang dimiliki masyarakat dalam memecahkan masalah dan memenuhi kebutuhan-kebutuhannya.

Pemberdayaan harus mampu menumbuh kembangkan segenap kemampuan dan kepercayaan diri masyarakat yang menunjang kemandirian mereka.

3) Perlindungan

Perlindungan berarti melindungi masyarakat terutama kelompokkelompok lemah agar tidak tertindas oleh kelompok kuat, menghindari terjadinya persaingan yang tidak seimbang (apalagi tidak sehat) antara yang kuat dan lemah, dan mencegah terjadinya eksploitasi kelompok kuat terhadap kelompok lemah. Pemberdayaan harus diarahkan kepada penghapusan segala jenis diskriminasi dan dominasi yang tidak menguntungkan rakyat kecil.

4) Penyokongan

Penyokongan yaitu memberikan bimbingan dan dukungan agar masyarakat mampu menjalankan perannya dan tugas-tugas kehidupannya. Pemberdayaan harus mampu menyokong masyarakat agar tidak terjatuh kedalam keadaan dan posisi yang semakin lemah dan terpinggirkan.

5) Pemeliharaan

Pemeliharaan yaitu memelihara kondisi yang kondusif agar tetap terjadi keseimbangan distribusi kekuasaan antara berbagai kelompok dalam masyarakat. Pemberdayaan harus mampu menjamin keselarasan dan keseimbangan yang memungkinkan setiap orang memperoleh kesempatan berusaha.

\section{Pemberdayaan Masyarakat}

Menurut Dubois dan Miley , 2005. menjelaskan empat cara dalam melakukan pemberdayan masyarakat, yaitu :

1) Membangun relasi pertolongan yang diwujudkan dalam bentuk merefeksikan respon rasa empati terhadap sasaran, menghargai pilihan dan hak klien/sasaran untuk menentukan nasibnya sendiri (self determination), menghargai perbedaan dan keunikan individu serta 
menekankan kerjasama klien (self partnerships).

2) Membangun komunikasi yang diwujudkan dalam bentuk menghormati dan harga diri klien/sasaran, mempertimbangkan keragaman individu, berfokus pada klien serta menjaga kerahasiaan yang dimiliki oleh klien/sasaran.

3) Terlibat dalam pemecahan masalah yang dapat diwujudkan dalam bentuk memperkuat partisipasi klien dalam semua aspek proses pemecahan masalah, mengharagai hak-hak klien, merangkai tantangan-tantangan sebagai kesempatan belajar serta melibatkan klien/sasaran dalam membuat keputusan dan kegiatan evaluasinya.

4) Merefleksikan sikap dan nilai profesi pekerjaan sosial yang diwujudkan dalam bentuk ketaatan terhadap kode etik profesi, keterlibatan dalam pengembangan profesional, melaakukan riset dan perumusan kebijakan, penerjemahan kesulitankesulitan pribadi ke dalam isu-isu publik serta penghapusan segala bentuk diskriminasi dan ketidakselarasan kesempatan.

\section{METODE PENELITIAN}

Berdasarkan permasalahan yang telah dikemukakan pendeskripsian dilakukan terkait dengan kajian nelayan tradisional pada wilayah Kota Padang di Kecamatan Rimbo Kaluang. Jumlah populasi nelayan tradisional sebanyak 137. Didasarkan pada tekhnik Observasi. Dalam penelitian ini menggunakan rancangan analisis deskriptif yaitu pengumpulan data untuk memberikan gambaran atau penegasan suatu konsep. Data yang dibutuhkan dalam penelitian ini meliputi, data primer dan data sekunder. Metode pengumpulan data primer meliputi, metode observasi lapangan. Sedangkan metode pengumpulan data sekunder meliputi, metode pencatatan dokumen.
HASIL DAN PEMBAHASAN

Untuk mengetahui Bagaimana upaya Pemerintah Kota Padang untuk meningkatkan penghasilan nelayan tradisional di pantai Muaro Lasak Kota Padang. Dalam melaksanakan pemberdayaan perlu dilakukan melalui berbagai penerapan pendekatan pemberdayaan dapat dilakukan melalui 5P, yaitu pemungkinan, penguatan, perlindungan, penyokongan dan pemeliharaan.(Suharto 2005:45). hasil penelitian ini diuraikan sebagai berikut:

\section{1) Pemungkinan}

Dengan dibuatnya Pantai Muaro Lasak sebagai objek wisata unggulan di Kota Padang saat ini membuat nelayan tradisional yang dahulunya menempatkan kapal di panati tersebut sekarang harus memindahkan kapalnya ke parit disebelahnya karena kios - kios yang berdiri disana mengambil tempat sampai ke tepi pantai sehingga nelayan tidak bisa memarkirkan kapal, menjemur jaring pukek dan kegiatan lainya karena wilayah tersebut telah di peruntukan untuk objeck wisata.

Dalam temuan penelitian pemerintah kota Padang sudah berupaya memberikan penempatan yang layak untuk nelayan tradisional dengan tetap mengosongkan area bawah jembatan dan timur pantai Muaro Lasak untuk dijadikan tempat aktifitas nelayan tradisional, meskipun sedikit mengalami kendala dan keluhan oleh nelayan - nelayan tersebut namun pada akhirnya nelayan telah menerima dan memahami potensi objek wisata pantai Muaro Lasak.

\section{2) Penguatan}

Dinas Kelautan dan Perikanan Kota Padang mempunyai Program Pengembangan Perikanan Tangkap atau di sebut P3T yang di ketuai oleh bapak Ir.Vebria Atori Putra. Dalam perjalananya P3T memberikan bantuang berupa perlengkapan nelayan untuk membantu nelayan - nelayan kecil di pantai Muaro Lasak. 
Ovael Sandro Melta, M. Fachri Adnan I Upaya Pemerintah Kota Padang dalam Memberdayakan Nelayan Tradisional di Pantai Muaro Lasak Kota Padang

Nelayan - nelayan di pantai muaro lasak atau bisa di sebut juga nelayan Rimbo Kaluang juga antusias akan P3T karena mereka merasa terbantu dengan adanya perlengkapan baru yang lebih bagus untuk membantu nelayan - nelayan untuk meningkatkan hasil tangkapnya, meskipun masih ada kekurangan dimana program P3T

Tabel 3. Daftar Kepemilikan Nelayan Tradisional Rimbo Kaluang

\begin{tabular}{|c|c|c|}
\hline No & Nama & $\begin{array}{c}\text { Status } \\
\text { Kepemilikan } \\
\text { Kapal }\end{array}$ \\
\hline 1 & $\begin{array}{l}\text { Yulius } \\
\text { Efendi }\end{array}$ & Memiliki API \\
\hline 2 & $\begin{array}{l}\text { Erwan } \\
\text { Ahmad }\end{array}$ & $\begin{array}{l}\text { Memiliki Kapal / } \\
\text { Perahu }\end{array}$ \\
\hline 3 & $\begin{array}{l}\text { Surya Andi } \\
\text { Nova }\end{array}$ & $\begin{array}{l}\text { Memiliki Kapal / } \\
\text { Perahu }\end{array}$ \\
\hline 4 & $\begin{array}{l}\text { Syahrul } \\
\text { Midan }\end{array}$ & $\begin{array}{l}\text { Memiliki Kapal / } \\
\text { Perahu }\end{array}$ \\
\hline 5 & $\begin{array}{l}\text { Muslim } \\
\text { Garibo }\end{array}$ & $\begin{array}{l}\text { Memiliki Kapal / } \\
\text { Perahu }\end{array}$ \\
\hline 6 & Afrizal & $\begin{array}{l}\text { Memiliki Kapal / } \\
\text { Perahu }\end{array}$ \\
\hline 7 & Anwar & $\begin{array}{l}\text { Tidak } \\
\text { Memiliki/Pekerja }\end{array}$ \\
\hline 8 & $\begin{array}{l}\text { Muhtar } \\
\text { Dami }\end{array}$ & $\begin{array}{l}\text { Tidak } \\
\text { Memiliki/Pekerja }\end{array}$ \\
\hline 9 & Meriko & $\begin{array}{l}\text { Tidak } \\
\text { Memiliki/Pekerja }\end{array}$ \\
\hline 10 & Nasrul & $\begin{array}{l}\text { Memiliki Kapal / } \\
\text { Perahu }\end{array}$ \\
\hline 11 & Syafril & $\begin{array}{l}\text { Memiliki Kapal / } \\
\text { Perahu }\end{array}$ \\
\hline 12 & Ali Usar & $\begin{array}{l}\text { Memiliki Kapal / } \\
\text { Perahu }\end{array}$ \\
\hline 13 & $\begin{array}{l}\text { Rudi } \\
\text { Chandra }\end{array}$ & $\begin{array}{l}\text { Memiliki Kapal / } \\
\text { Perahu }\end{array}$ \\
\hline 14 & Hendri & $\begin{array}{l}\text { Memiliki Kapal / } \\
\text { Perahu }\end{array}$ \\
\hline 15 & Syamsuardi & $\begin{array}{l}\text { Memiliki Kapal / } \\
\text { Perahu }\end{array}$ \\
\hline 16 & Syahril & $\begin{array}{l}\text { Memiliki Kapal / } \\
\text { Perahu }\end{array}$ \\
\hline 17 & Ramli & $\begin{array}{l}\text { Memiliki Kapal / } \\
\text { Perahu }\end{array}$ \\
\hline
\end{tabular}

terkadang tidak memberi bantuan sesuai dengan kebutuhan nelayan. Berikut data nelayan tradisional yang tercatat oleh Dinas Kelautan dan Perikanan Kota Padang tentang status kepemiikan kapal dan perahu sebagai pedoman penerimaan bantuan, bia dilihat dalam tabel berikut ini:

\begin{tabular}{|c|c|c|}
\hline$\overline{18}$ & Djamalus & $\begin{array}{l}\text { Memiliki Kapal / } \\
\text { Perahu }\end{array}$ \\
\hline 19 & Junaidi & $\begin{array}{l}\text { Tidak } \\
\text { Memiliki/Pekerja }\end{array}$ \\
\hline 20 & $\begin{array}{l}\text { Syamsir } \\
\text { Acin }\end{array}$ & $\begin{array}{l}\text { Memiliki Kapal / } \\
\text { Perahu }\end{array}$ \\
\hline 21 & Budiman & $\begin{array}{l}\text { Memiliki Kapal / } \\
\text { Perahu }\end{array}$ \\
\hline 22 & Iswanto & $\begin{array}{l}\text { Memiliki Kapal / } \\
\text { Perahu }\end{array}$ \\
\hline 23 & $\begin{array}{l}\text { Andri } \\
\text { Nasrizal }\end{array}$ & $\begin{array}{l}\text { Memiliki Kapal / } \\
\text { Perahu }\end{array}$ \\
\hline 24 & Nawir & $\begin{array}{l}\text { Memiliki Kapal / } \\
\text { Perahu }\end{array}$ \\
\hline 25 & $\begin{array}{l}\text { Antonio } \\
\text { Carlos }\end{array}$ & $\begin{array}{l}\text { Memiliki Kapal / } \\
\text { Perahu }\end{array}$ \\
\hline 26 & Erizal & $\begin{array}{l}\text { Memiliki Kapal / } \\
\text { Perahu }\end{array}$ \\
\hline 27 & Masrul Guci & $\begin{array}{l}\text { Memiliki Kapal / } \\
\text { Perahu }\end{array}$ \\
\hline 28 & $\begin{array}{l}\text { M.danir } \\
\text { Ishak }\end{array}$ & $\begin{array}{l}\text { Memiliki Kapal / } \\
\text { Perahu }\end{array}$ \\
\hline 29 & Melia Tasni & $\begin{array}{l}\text { Memiliki Kapal / } \\
\text { Perahu }\end{array}$ \\
\hline 30 & Yusmanidar & $\begin{array}{l}\text { Memiliki Kapal / } \\
\text { Perahu }\end{array}$ \\
\hline 31 & Alisman & $\begin{array}{l}\text { Tidak } \\
\text { Memiliki/Pekerja }\end{array}$ \\
\hline 32 & Abunawas & $\begin{array}{l}\text { Memiliki Kapal / } \\
\text { Perahu }\end{array}$ \\
\hline 33 & Irwandi & $\begin{array}{l}\text { Memiliki Kapal / } \\
\text { Perahu }\end{array}$ \\
\hline 34 & $\begin{array}{l}\text { Rafrino } \\
\text { Pendi }\end{array}$ & $\begin{array}{l}\text { Memiliki Kapal / } \\
\text { Perahu }\end{array}$ \\
\hline 35 & Ali Sakban & $\begin{array}{l}\text { Memiliki Kapal / } \\
\text { Perahu }\end{array}$ \\
\hline 36 & Maiyulis. B & $\begin{array}{l}\text { Tidak } \\
\text { Memiliki/Pekerja }\end{array}$ \\
\hline
\end{tabular}


Ovael Sandro Melta, M. Fachri Adnan| Upaya Pemerintah Kota Padang dalam Memberdayakan Nelayan Tradisional di Pantai Muaro Lasak Kota Padang

\begin{tabular}{|c|c|c|c|c|c|}
\hline 37 & Zainudin & $\begin{array}{l}\text { Memiliki Kapal / } \\
\text { Perahu }\end{array}$ & $\overline{61}$ & Sonia & $\begin{array}{l}\text { Tidak } \\
\text { Memiliki/Pekerja }\end{array}$ \\
\hline 38 & Irwan & $\begin{array}{l}\text { Tidak } \\
\text { Memiliki/Pekerja }\end{array}$ & 62 & Rustam & $\begin{array}{l}\text { Tidak } \\
\text { Memiliki/Pekerja }\end{array}$ \\
\hline 39 & Azwardi & $\begin{array}{l}\text { Tidak } \\
\text { Memiliki/Pekerja }\end{array}$ & 63 & D. Nanda. P & $\begin{array}{l}\text { Memiliki Kapal / } \\
\text { Perahu }\end{array}$ \\
\hline 40 & Syafruddin & $\begin{array}{l}\text { Tidak } \\
\text { Memiliki/Pekerja }\end{array}$ & 64 & Hendra & $\begin{array}{l}\text { Tidak } \\
\text { Memiliki/Pekerja }\end{array}$ \\
\hline 41 & Amrizal & $\begin{array}{l}\text { Tidak } \\
\text { Memiliki/Pekerja }\end{array}$ & 65 & Hendra. S & $\begin{array}{l}\text { Tidak } \\
\text { Memiliki/Pekerja }\end{array}$ \\
\hline 42 & Nasrul & $\begin{array}{l}\text { Tidak } \\
\text { Memiliki/Pekerja }\end{array}$ & 66 & Sukin & $\begin{array}{l}\text { Memiliki Kapal / } \\
\text { Perahu }\end{array}$ \\
\hline 43 & Rafli & $\begin{array}{l}\text { Memiliki Kapal / } \\
\text { Perahu }\end{array}$ & 67 & $\begin{array}{l}\text { Beni } \\
\text { Sumardi }\end{array}$ & $\begin{array}{l}\text { Memiliki Kapal / } \\
\text { Perahu }\end{array}$ \\
\hline 44 & Ali Luddin & $\begin{array}{l}\text { Memiliki Kapal / } \\
\text { Perahu }\end{array}$ & 68 & Antoni & $\begin{array}{l}\text { Memiliki Kapal / } \\
\text { Perahu }\end{array}$ \\
\hline 45 & Syahril & $\begin{array}{l}\text { Memiliki Kapal / } \\
\text { Perahu }\end{array}$ & 69 & Yasmon & $\begin{array}{l}\text { Memiliki Kapal / } \\
\text { Perahu }\end{array}$ \\
\hline 46 & Ermendra & $\begin{array}{l}\text { Memiliki Kapal / } \\
\text { Perahu }\end{array}$ & 70 & $\begin{array}{l}\text { Erwan } \\
\text { Ahmad }\end{array}$ & $\begin{array}{l}\text { Memiliki Kapal / } \\
\text { Perahu }\end{array}$ \\
\hline 47 & Taspredi & $\begin{array}{l}\text { Tidak } \\
\text { Memiliki/Pekerja }\end{array}$ & 71 & Yulhendri & $\begin{array}{l}\text { Tidak } \\
\text { Memiliki/Pekerja }\end{array}$ \\
\hline 48 & Solikin & $\begin{array}{l}\text { Memiliki Kapal / } \\
\text { Perahu }\end{array}$ & 72 & Jeriko & $\begin{array}{l}\text { Memiliki Kapal / } \\
\text { Perahu }\end{array}$ \\
\hline 49 & Amrizal & $\begin{array}{l}\text { Tidak } \\
\text { Memiliki/Pekerja }\end{array}$ & 73 & Jon Kenidi & $\begin{array}{l}\text { Memiliki Kapal / } \\
\text { Perahu }\end{array}$ \\
\hline 50 & $\begin{array}{l}\text { Dian } \\
\text { Syofyan }\end{array}$ & $\begin{array}{l}\text { Memiliki Kapal / } \\
\text { Perahu }\end{array}$ & 74 & Irawan & $\begin{array}{l}\text { Tidak } \\
\text { Memiliki/Pekerja }\end{array}$ \\
\hline 51 & Zainul & $\begin{array}{l}\text { Tidak } \\
\text { Memiliki/Pekerja }\end{array}$ & 75 & Afrizal & $\begin{array}{l}\text { Memiliki Kapal / } \\
\text { Perahu }\end{array}$ \\
\hline 52 & M. Sayahril & $\begin{array}{l}\text { Tidak } \\
\text { Memiliki/Pekerja }\end{array}$ & 76 & Jainuar & $\begin{array}{l}\text { Tidak } \\
\text { Memiliki/Pekerja }\end{array}$ \\
\hline 53 & Yonedi & $\begin{array}{l}\text { Memiliki Kapal / } \\
\text { Perahu }\end{array}$ & 77 & Azwardi & $\begin{array}{l}\text { Memiliki Kapal / } \\
\text { Perahu }\end{array}$ \\
\hline 54 & Ishak & $\begin{array}{l}\text { Tidak } \\
\text { Memiliki/Pekerja }\end{array}$ & 78 & Masrizal & $\begin{array}{l}\text { Tidak } \\
\text { Memiliki/Pekerja }\end{array}$ \\
\hline 55 & $\begin{array}{l}\text { Syahrun } \\
\text { Midan }\end{array}$ & $\begin{array}{l}\text { Tidak } \\
\text { Memiliki/Pekerja }\end{array}$ & 79 & Zainuddin & $\begin{array}{l}\text { Tidak } \\
\text { Memiliki/Pekerja }\end{array}$ \\
\hline 56 & $\begin{array}{l}\text { Rudi } \\
\text { Hartono }\end{array}$ & $\begin{array}{l}\text { Memiliki Kapal / } \\
\text { Perahu }\end{array}$ & 80 & Indra Putra & $\begin{array}{l}\text { Tidak } \\
\text { Memiliki/Pekerja }\end{array}$ \\
\hline 57 & Anto & $\begin{array}{l}\text { Tidak } \\
\text { Memiliki/Pekerja }\end{array}$ & 81 & $\begin{array}{l}\text { Ahmad } \\
\text { Yanuar }\end{array}$ & $\begin{array}{l}\text { Memiliki Kapal / } \\
\text { Perahu }\end{array}$ \\
\hline 58 & Erwandi & $\begin{array}{l}\text { Memiliki Kapal / } \\
\text { Perahu }\end{array}$ & 82 & Anuar & $\begin{array}{l}\text { Memiliki Kapal / } \\
\text { Perahu }\end{array}$ \\
\hline 59 & Gustian. H & $\begin{array}{l}\text { Tidak } \\
\text { Memiliki/Pekerja }\end{array}$ & 83 & Tedi & $\begin{array}{l}\text { Memiliki Kapal / } \\
\text { Perahu }\end{array}$ \\
\hline 60 & Afrizal & $\begin{array}{l}\text { Memiliki Kapal / } \\
\text { Perahu }\end{array}$ & 84 & Zulkenidi & $\begin{array}{l}\text { Tidak } \\
\text { Memiliki/Pekerja }\end{array}$ \\
\hline
\end{tabular}


Ovael Sandro Melta, M. Fachri Adnan| Upaya Pemerintah Kota Padang dalam Memberdayakan Nelayan Tradisional di Pantai Muaro Lasak Kota Padang

\begin{tabular}{|c|c|c|c|c|c|}
\hline$\overline{85}$ & Hengki & $\begin{array}{l}\text { Tidak } \\
\text { Memiliki/Pekerja }\end{array}$ & 109 & Herman & $\begin{array}{l}\text { Tidak } \\
\text { Memiliki/Pekerja }\end{array}$ \\
\hline 86 & $\begin{array}{l}\text { Deni } \\
\text { Agustian }\end{array}$ & $\begin{array}{l}\text { Memiliki Kapal / } \\
\text { Perahu }\end{array}$ & 110 & Husin & $\begin{array}{l}\text { Tidak } \\
\text { Memiliki/Pekerja }\end{array}$ \\
\hline 87 & Lukaman & $\begin{array}{l}\text { Memiliki Kapal / } \\
\text { Perahu }\end{array}$ & 111 & Hari & $\begin{array}{l}\text { Memiliki Kapal / } \\
\text { Perahu }\end{array}$ \\
\hline 88 & Wendri & $\begin{array}{l}\text { Memiliki Kapal / } \\
\text { Perahu }\end{array}$ & 112 & Jamaluddin & $\begin{array}{l}\text { Tidak } \\
\text { Memiliki/Pekerja }\end{array}$ \\
\hline 89 & Hendri & $\begin{array}{l}\text { Tidak } \\
\text { Memiliki/Pekerja }\end{array}$ & 113 & Jufri & $\begin{array}{l}\text { Memiliki Kapal / } \\
\text { Perahu }\end{array}$ \\
\hline 90 & Masrizal. T & $\begin{array}{l}\text { Memiliki Kapal / } \\
\text { Perahu }\end{array}$ & 114 & Junaidi & $\begin{array}{l}\text { Memiliki Kapal / } \\
\text { Perahu }\end{array}$ \\
\hline 91 & Benny & $\begin{array}{l}\text { Tidak } \\
\text { Memiliki/Pekerja }\end{array}$ & 115 & Muchlis & $\begin{array}{l}\text { Memiliki Kapal / } \\
\text { Perahu }\end{array}$ \\
\hline 92 & Purwanto & $\begin{array}{l}\text { Tidak } \\
\text { Memiliki/Pekerja }\end{array}$ & 116 & Mansur & $\begin{array}{l}\text { Tidak } \\
\text { Memiliki/Pekerja }\end{array}$ \\
\hline 93 & Risman & $\begin{array}{l}\text { Memiliki Kapal / } \\
\text { Perahu }\end{array}$ & 117 & Masrianto & $\begin{array}{l}\text { Memiliki Kapal / } \\
\text { Perahu }\end{array}$ \\
\hline 94 & Dasril Anta & $\begin{array}{l}\text { Tidak } \\
\text { Memiliki/Pekerja }\end{array}$ & 118 & Makmur & $\begin{array}{l}\text { Memiliki Kapal / } \\
\text { Perahu }\end{array}$ \\
\hline 95 & Basrial & $\begin{array}{l}\text { Memiliki Kapal / } \\
\text { Perahu }\end{array}$ & 119 & $\begin{array}{l}\text { Abdul } \\
\text { Wahid }\end{array}$ & $\begin{array}{l}\text { Tidak } \\
\text { Memiliki/Pekerja }\end{array}$ \\
\hline 96 & Ramli & $\begin{array}{l}\text { Memiliki Kapal / } \\
\text { Perahu }\end{array}$ & 120 & Herizal. M & $\begin{array}{l}\text { Memiliki Kapal / } \\
\text { Perahu }\end{array}$ \\
\hline 97 & $\begin{array}{l}\text { Zulmadi } \\
\text { Oyon }\end{array}$ & $\begin{array}{l}\text { Memiliki Kapal / } \\
\text { Perahu }\end{array}$ & 121 & $\begin{array}{l}\text { T. Indra } \\
\text { Putrawan }\end{array}$ & $\begin{array}{l}\text { Tidak } \\
\text { Memiliki/Pekerja }\end{array}$ \\
\hline 98 & Syuyanto & $\begin{array}{l}\text { Memiliki Kapal / } \\
\text { Perahu }\end{array}$ & 122 & Zainuddin & $\begin{array}{l}\text { Tidak } \\
\text { Memiliki/Pekerja }\end{array}$ \\
\hline 99 & $\begin{array}{l}\text { Armen } \\
\text { Amran }\end{array}$ & $\begin{array}{l}\text { Memiliki Kapal / } \\
\text { Perahu }\end{array}$ & 123 & Jhon Kenedi & $\begin{array}{l}\text { Tidak } \\
\text { Memiliki/Pekerja }\end{array}$ \\
\hline 100 & Hermansyah & $\begin{array}{l}\text { Memiliki Kapal / } \\
\text { Perahu }\end{array}$ & 124 & Sutarno & $\begin{array}{l}\text { Memiliki Kapal / } \\
\text { Perahu }\end{array}$ \\
\hline 101 & Ismanto & $\begin{array}{l}\text { Memiliki Kapal / } \\
\text { Perahu }\end{array}$ & 125 & $\begin{array}{l}\text { Andri } \\
\text { Yandri }\end{array}$ & $\begin{array}{l}\text { Tidak } \\
\text { Memiliki/Pekerja }\end{array}$ \\
\hline 102 & Afrizal & $\begin{array}{l}\text { Memiliki Kapal / } \\
\text { Perahu }\end{array}$ & 126 & Bambang & $\begin{array}{l}\text { Tidak } \\
\text { Memiliki/Pekerja }\end{array}$ \\
\hline 103 & $\begin{array}{l}\text { Ari } \\
\text { Kurniawan }\end{array}$ & $\begin{array}{l}\text { Memiliki Kapal / } \\
\text { Perahu }\end{array}$ & 127 & $\begin{array}{l}\text { Robi Eka } \\
\text { Putra }\end{array}$ & $\begin{array}{l}\text { Tidak } \\
\text { Memiliki/Pekerja }\end{array}$ \\
\hline 104 & $\begin{array}{l}\text { Amran } \\
\text { Caniago }\end{array}$ & $\begin{array}{l}\text { Memiliki Kapal / } \\
\text { Perahu }\end{array}$ & 128 & Idris & $\begin{array}{l}\text { Memiliki Kapal / } \\
\text { Perahu }\end{array}$ \\
\hline 105 & $\begin{array}{l}\text { Boby } \\
\text { Taqqwakal }\end{array}$ & $\begin{array}{l}\text { Memiliki Kapal / } \\
\text { Perahu }\end{array}$ & 129 & Lukman & $\begin{array}{l}\text { Memiliki Kapal / } \\
\text { Perahu }\end{array}$ \\
\hline 106 & Dirman & $\begin{array}{l}\text { Memiliki Kapal / } \\
\text { Perahu }\end{array}$ & 130 & Masril & $\begin{array}{l}\text { Tidak } \\
\text { Memiliki/Pekerja }\end{array}$ \\
\hline 107 & Defrizal & $\begin{array}{l}\text { Memiliki Kapal / } \\
\text { Perahu }\end{array}$ & 131 & Yulianto & $\begin{array}{l}\text { Tidak } \\
\text { Memiliki/Pekerja }\end{array}$ \\
\hline 108 & Pendi & $\begin{array}{l}\text { Tidak } \\
\text { Memiliki/Pekerja }\end{array}$ & 132 & Lukman & $\begin{array}{l}\text { Memiliki Kapal / } \\
\text { Perahu }\end{array}$ \\
\hline
\end{tabular}


Ovael Sandro Melta, M. Fachri Adnan| Upaya Pemerintah Kota Padang dalam Memberdayakan Nelayan Tradisional di Pantai Muaro Lasak Kota Padang

\begin{tabular}{lll}
\hline 133 & Syafruddin & Memiliki Kapal / \\
& & Perahu \\
134 & Hengki & Memiliki Kapal / \\
& & Perahu \\
135 & Amrizal & $\begin{array}{l}\text { Memiliki Kapal / } \\
\text { Perahu }\end{array}$ \\
\hline
\end{tabular}

Berdasarkan tabel diatas diketahui sebanyak 137 nelayan memiliki status kepemilikan kapal dan pekerja yang bermacam - macam. Hal tersebut menjadi panduan oleh Dinas Kelautan dan Perikanan Kota Padang untuk mengerahui nelayan tersebut layak atau tidak tidak untuk di tindak lanjuti sebagai peneriman bantuan P3T. dengan begitu nelayan nelayan tradisional yang telah menerima kecukupan akan dianggap berhasil melakukan program P3T dengan baik karena mampu mandiri untuk mengembangkan bantuan yang ada.

\section{3) Perlindungan}

Ada 2 jenis nelayan yang beroperasi di Kota Padang yaitu nelayan tradisional atau nelayan kecil dan nelayan bagan atau nelayan besar, berdasarkan temuan penelitian kedua nelayan ini mengalami masalah akan zona tangkap yang dimana hal itu justru merugikan nelayan tradisional karena nelayan bagan mengambil ikan di dalam zona tangkap nelayan kecil.

Ibuk Ir.Elvy Junaina sebagai kepala Sapras dan budidaya di Dinas Kelautan dan Perikanan kota Padang membantu nelayan nelayan kecil tersebut dengan melaporkan ke TNI - AL dan Dinas Kelautan dan Perikanan Provinsi Sumatera Barat untuk sama - sama mengawasi tentang penegakan jalur tangkap supaya tidak ada pihak yang terugikan dalam aktifitas melaut untuk menangkap ikan.

\section{4) Penyokongan}

Program Pengembangan Perikanan Tangkap atau P3T selain meberikan bantuan berupa perlengkapan juga memberikan sosialisasi cara mengelolah ikan yang didapatkan supaya nelayan mampu membentuk keuanganya sendiri secara mandiri untuk mampu memperbaiki kapal dan membeli keperluan lainya.

\begin{tabular}{lll}
\hline 136 & Wendri & Tidak \\
& & Memiliki/Pekerja \\
137 & Junaidi & Tidak \\
& & Memiliki/Pekerja \\
\hline
\end{tabular}

Penyokongan ini dilakukan langsung oleh pemerintah kota Padang dengan melakukan pertemuan sekali sebulan untuk melakukan sesi musyawarah, ini biasa dilakukan di mushola terdekat di kecamatan Rimbo Kaluang itu sendiri.

\section{5) Pemeliharaan}

Program Pengembangan Perikanan Tangakap atau P3T merupakan program Dinas Kelautan dan Perikanan Kota Padang bertujuan untuk membentuk masyarkat nelayan yang mandiri dan mampu mengembangkan banyak potensi lainya untuk bisa meningkatkan penghasilanya sendiri.

Nelayan diharapkan mampu berkembang dan menjadi lebih mandiri maka dari itu dengan adanya kelompok kelompok nelayan yang di ketuai 2 orang yaitu bapak Muslim Garibo dan Yuluis Efendi diharapkan bisa menjadi penyalur pemikiran untuk nelayan - nelayan kecil di pantai Muaro Lasak.

\section{PENUTUP}

Berdasarkan hasil penyajian data dan pembahasan, maka dapat disimpulkan sebagai berikut:

Pertama nelayan - nelayan di pantai Muaro Lasak kota Padang mengalami masalah akan tempat beraktifitas yang biasa ditempati sekarang telah menjadi objek wisata dengan kios - kios makanan yang tersebar luas sehingga menutupi sebagian besar wilayah pesisir sehingga nelayan tidak bisa memakirkan kapal di tepi pantai dan tidak bisa menjemur perlengkapan nelayanya.

Kedua adanya pelanggaran zona tangkap yang dilakukan nelayan bagan dan mengambil ikan di rumpun - rumpun yang merupakan dipertujukan untuk 
Ovael Sandro Melta, M. Fachri Adnan| Upaya Pemerintah Kota Padang dalam Memberdayakan Nelayan Tradisional di Pantai Muaro Lasak Kota Padang

mengumpulkan ikan untuk mempermudah nelayan tradisional menangkap ikan disana. Nelayan tradisional Rimbo Kaluang mengalami kesulitan mendapatkan penghasilan yang cukup untuk merawat kapal dan kehidupanya dan mengembangkan hasil ikanya.

Ketiga Program Pengembangan Perikanan Tangkap bertujuan membantu masalah masalah nelayan tradisional di pantai Muaro Lasak dengan memberikan sosialisasi dan memberikan informasi juga bantuan berupa mesin dan jaring dengan tujuan nelayan mampu mengembangkan bantuan tersebut dengan baik.

\section{DAFTAR KEPUSTAKAAN}

Anonim,2011.repository.upi.edu/operator/ upload/s_geo_046022_chapter2.pdf., Diakses pada 11 februari 2013.

Badan Pusat Statistik, 2011. BPS.go.id : diakses pada 14 februari 2019.

Dahuri,Rokhmin.2001. Pengelolaan sumber daya wilayah pesisir dan lautan secara terpadu.

Dinas Perikanan dan Kelautan, 011. Data statistik perikanan kabupaten buleleng 2011.

Kusnadi, 2003 ; Akar Kemiskinan Nelayan. Yogyakarta : LkiS.

Muhyadi, 1990. organisasi, teori, struktur dan proses : FPIPS, IKIP YOGYAKARTA.

Nadia Watung, C. D. O. K. (2013). Karakteristik Sosial Ekonomi Masyarakat Nelayan Di Desa Lopana Kecamatan Amurang Timur Propinsi Sulawesi Utara. Akulturasi, 1(2), 9-12.

Nucifera, A., Silmi, N., Wiyono, E. S., \& Wisudo, S. H. (2018). POLA BAGI HASIL TANGKAPAN IKAN NELAYAN PANCING di CISOLOK Oleh: Mahasiswa Magister Program Studi
Teknologi Perikanan Laut, Sekolah Pascasarjana IPB.

Program, A., Agribisnis, S., Pertanian, F., Utara, S., Utara, U. S., \& Utara, U. S. (n.d.). PENDAPATAN NELAYAN DI DESA BOGAK , KECAMATAN TANJUNG TIRAM , KABUPATEN BATU BARA Rizky Pratama *), Diana Chalil**), Emalisa ***).

Sipahelut, Michel. 2010. Analisis pemberdayaan masyarakat nelayan di kecamatan tobelo.

Soediyono, Reksoprayitno. 2009. Ekonomi Makro. Badan Penerbit Fakultas Ekonomi. Yogyakarta: BPFEUGM.

Todaro, Michael P. 2003. Pembangunan Ekonomi Di Dunia Ketiga. Alih Bahasa: Yogyakarta: BPFE-UGM.

Van Tilburg A.,E.Udong., dan A.Niehof.2009. Struggle for Survival: Women Fish Traders Fighting and Cultural ontrainsts in Fishing Communities in the Niger Delta, Nigeria. The University of Hamburg.

Widodo, S. 2011. „Strategi Nafkah Berkelanjutan Bagi Rumah Tangga Miskin Di Daerah Pesisiree. Jurnal Makara, Seri Sosial Humaniora. 15(1):10-20. Bangkalan: Fakultas Pertanian Universitas Trunojoyo. 